\title{
Traditional and Complementary Medicine: Perspective of patients in Sabah, Malaysia
}

\author{
Che Noriah Othman, Maryam Farooqui \\ Faculty of Pharmacy \\ UiTM Pulau Pinang, Bertam Campus, 13200, Pulau Pinang, Malaysia. \\ chenoriah.othman@ppinang.uitm.edu.my
}

\begin{abstract}
This study was conducted to evaluate the knowledge and perception on the use of (T\&CM) and reasons for usage among patients visiting one government hospital in Malaysia. Self-administered questionnaires were distributed to 384 participants. Result showed that the majority of the participants reported using T\&CM as an additive to their conventional medicines. Even though, most participants understood of the possible interactions that might occur, when combining T\&CM with conventional medicines they remain dedicated to their practice. More study on T\&CM should be conducted to ensure the accurate and trusted scientific evidence provided especially in term of safety and efficacy.

Keywords: Traditional and Complementary Medicine, Malaysian Health Care, Traditional practices, Conventional Medicine.

eISSN 2514-7528 @ 2018. The Authors. Published for AMER ABRA cE-Bs by e-International Publishing House, Ltd., UK. This is an open-access article under the CC BY-NC-ND license (http://creativecommons.org/licenses/bync-nd/4.0/). Peer-review under responsibility of AMER (Association of Malaysian Environment-Behaviour Researchers), ABRA (Association of Behavioural Researchers on Asians) and CE-Bs (Centre for EnvironmentBehaviour Studies), Faculty of Architecture, Planning \& Surveying, Universiti Teknologi MARA, Malaysia.
\end{abstract}

DOI: https://doi.org/10.21834/jabs.v3i10.317 


\subsection{Introduction}

Traditional and complementary medicine (T\&CM) is a group of practice introduced in an earlier era and has been gaining popularity all over the world including Malaysia. The growth of T\&CM in the market, easy access, and cheaper price has opted patients for T\&CM services. Moreover, the fears of hospital treatment, long wait for the treatment and the long queue to get medicine drive people more toward T\&CM.

The perception that T\&CM has little side effect on makes it become a significant contributor to the disease treatment. Moreover, the advertisement in the market had influenced patients tremendously and contributed to the increase in T\&CM demand. This significant contributor led to a resurgence of interest in the traditional form of health care and had led to the growth in research, new services and administrative program. The traditional practitioners are more accepted and recognize at least as a primary health care providers by Malaysian health care team (Lao et al., 1995).

Encouragement to use T\&CM not just come from the family sometimes they received the suggestion from their close friends and also by doctors of pharmacists as patients last option (Lee et al., 2004).

The establishment of T\&CM in Malaysia with full scientific evidence on safety and efficacy are still lacking. The risk of the interaction between T\&CM and modern medicine is not well documented. However, with this lacking information, patients are using both groups of medication routinely for the treatment of their disease. No sufficient data is available on the prevalence of use of T\&CM and sources of T\&CM obtained. The data on the number of patients using the drug in combination to treat their diseases also is not available. This study was conducted to estimate the prevalent of use of T\&CM medicine among patients who attended government hospital for their health problem. At the same time, we were also determining the percentage of T\&CM uses in concurrent with the modern/conventional medicine. This result will be useful for the Health care team to increase the awareness program for the patients or to strategies the treatment modalities for patients attending government hospital in Malaysia.

\subsection{Literature Review}

T\&CM is aform of health-related practice design to prevent, treat and/or manage illnesses and/or preserve the mental and physical well-being of individuals" (T\&CM Division, Ministry of the Health Malaysia, 2007). It includes practices such as traditional Malay medicine, traditional Chinese medicine, traditional Indian medicine, homeopathy and complementary therapies and include medical or dental practice utilize by registered medical or dental practitioners.

T\&CM practice among Malaysian is common (Siti Z.M. 2009) due to its low cost and the presence of undesirable side effects is rare. Medical Research Institute Kuala Lumpur Malaysia showed that there was a high prevalence of T\&CM usage by Malaysian population particularly in the herb-based therapies for their health issues and health maintenance. 
The purpose of this study was to evaluate the T\&CM usage amongst patients attending government hospital in East Malaysia. The following objectives were set to meet the purpose of the study:

To determine the percentage of patients who use T\&CM concurrently with prescribed medicine.

To determine the factors that cause patients to use T\&CM.

To study patients' perception on the effect of T\&CM on their health status.

To assess patients' knowledge on possible interaction between prescribed medications and traditional medicine.

To determine whether patients are aware of other ways to improve the effectiveness of a treatment or maintenance of their health other than taking the prescribed medicines or traditional medicines.

\subsection{Methodology}

This study involved inpatients and patients attending emergency pharmacy at one government hospital in Malaysia from September to December 2012.

A set of questionnaires that consist of demography data T\&CM usage were distributed to the patients. Ethical approval was obtained from the Hospital Director and limited to the sample size calculated. Based on our calculation using Raosoft, we should have approximately 384 respondents to be included. Patients who are less than 12 years old age, unable to speak, and cannot communicate in Bahasa Malaysia were excluded from this study to prevent the vague outcome. The patients were randomly selected during the clinic days and accumulated until the targeted sample size achieved.

Data were analyzed using SPSS package version 20 and Microsoft Excell 2007.

\subsection{Results and Discussions.}

Demographical female were dominating as respondents $(54.42 \% \mathrm{n}=209)$. The age range were $12.76 \%$ (<20 years old), $26.3 \%$ (20 to 29 years old) $15.3 \%$ ( 30 to 39 years old), $20.05 \%$ (50 to 59 years old) and $8.33 \%$ were above 60 years old (Table 4.1 and 4.2 ). In term of race $20.31 \%$ respondents were Malays, $64.06 \%$ were Sabah Native, $7.55 \%$ were Chinese, $0.52 \%$ were Indian and $7.55 \%$ were other races (Table 4.3 ).

Reveal the results, discuss accordingly, and the implications.

Table 1: Gender of respondents and the use of T\&CM.

\begin{tabular}{ccccc}
\hline & \multicolumn{3}{c}{ Gender } & Total \\
\hline & & Male & Female & \\
The percentage of T\&CM usage & Yes & 168 & 137 & $305(79.43 \%)$ \\
& No & 41 & 38 & $79(20.5 \%)$ \\
Total & & $209(54.42 \%)$ & $175(45.58 \%)$ & $384(100 \%)$ \\
\hline
\end{tabular}


Table 1 shows the total number of respondents on the use of T\&CM based on their gender. There were $79.43 \%(n=305)$ respondents claimed that they had used T\&CM before while $79(20.5 \%)$ of them stated that they had never used them. However, there is no significant different in term of opinion between males and females regarding T\&CM usage. $(P>0.05)$.

Table 2: Age group of respondents and their T\&CM usage.

Using of T\&CM and age group

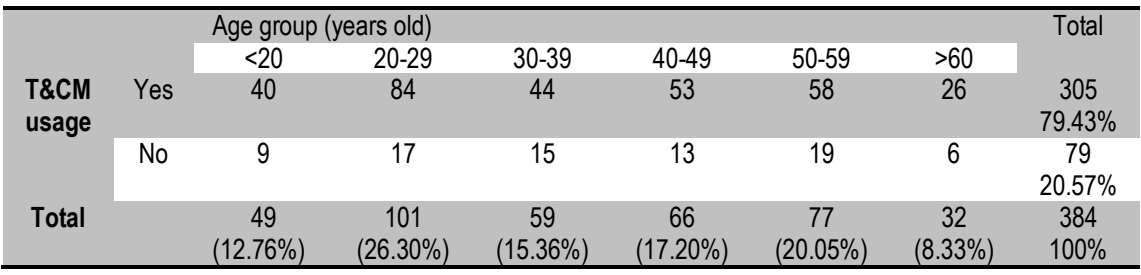

Table 2 shows the age group of all respondents. Young adult at the age of 20 to 29 was the major users. Senior citizen (age > 60 years old) were the least users. However, our finding suggested that the Malaysian populations at the study location are using T\&CM regardless of their adult age group.

Table 3: Race of respondents and the use of T\&CM.

\begin{tabular}{|c|c|c|c|c|c|c|c|}
\hline \multicolumn{8}{|c|}{ Using of T\&CM and ethnic group } \\
\hline & & \multicolumn{5}{|c|}{ Race } & \multirow[t]{2}{*}{ Total } \\
\hline & & Malay & $\begin{array}{l}\text { Sabah } \\
\text { Native }\end{array}$ & Chinese & Indian & Others & \\
\hline \multirow[t]{2}{*}{$\begin{array}{c}\text { Using of } \\
\text { T\&CM }\end{array}$} & Yes & 64 & 205 & 13 & 2 & 21 & $\begin{array}{c}305 \\
(79.3 \%)\end{array}$ \\
\hline & No & 14 & 41 & 16 & 0 & 8 & $\begin{array}{c}79 \\
(20.57 \%)\end{array}$ \\
\hline Total & & $\begin{array}{c}78 \\
20.31 \%\end{array}$ & $\begin{array}{c}246 \\
(64.06 \%)\end{array}$ & $\begin{array}{c}29 \\
(7.55 \%)\end{array}$ & $\begin{array}{c}2 \\
(0.52 \%)\end{array}$ & $\begin{array}{c}29 \\
(7.55 \%)\end{array}$ & $\begin{array}{c}384 \\
(100 \%)\end{array}$ \\
\hline
\end{tabular}

Sabah Native was the highest users of T\&CM $(p<0.05)$ followed by Malay users. However, all races in Sabah have used T\&CM in the past 12 months (Table 3).

Figure 1 reveals the most common type of T\&CM products used by respondents. Traditional products were mostly used. Traditional products claimed include traditionallyformulated oils and balms such as "gamat oil" and "tiger balm." Vitamins and supplements were the next most frequently used by respondents. Herbs were utilized as health maintenance modalities. Herbs commonly used were ginseng, Tongkat Ali and Pennywort. 


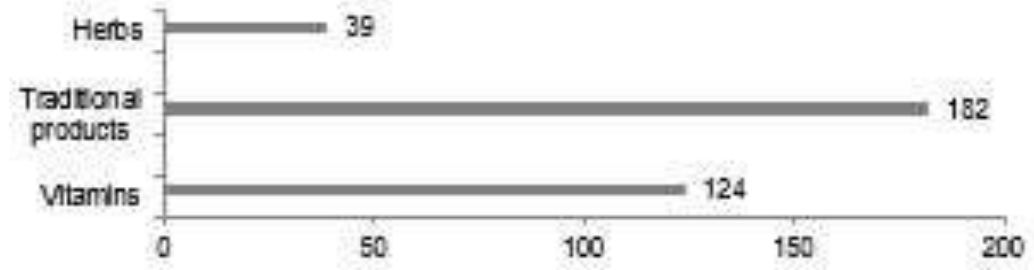

Figure 1: Types of T\&CM products used versus the number of respondents.



Figure 2: Reason for using T\&CM versus percentage of respondents.

Figure 4.2 shows the reason for using T\&CM. Respondents use T\&CM either for the treatment of their disease, health maintenance or both. However,a high percentage of respondents stated that they use T\&CM for the disease treatment $(66.5 \%)$ and $p<0.05$, followed by as health maintenance $(30.49 \%)$ and only a small percentage $(2.95 \%)$ use T\&CM for both reasons.

Figure 3 shows the factors that influence respondents for choosingT\&CM. Majority of respondents were influenced by their family and friends. Some of them were suggested by their doctors or pharmacist. Cultural belief was one of the influencing factors for them to take T\&CM. However, a small percentage of them choosingT\&CM for other reasons other than described above. Some of them took T\&CM as their last choice. 


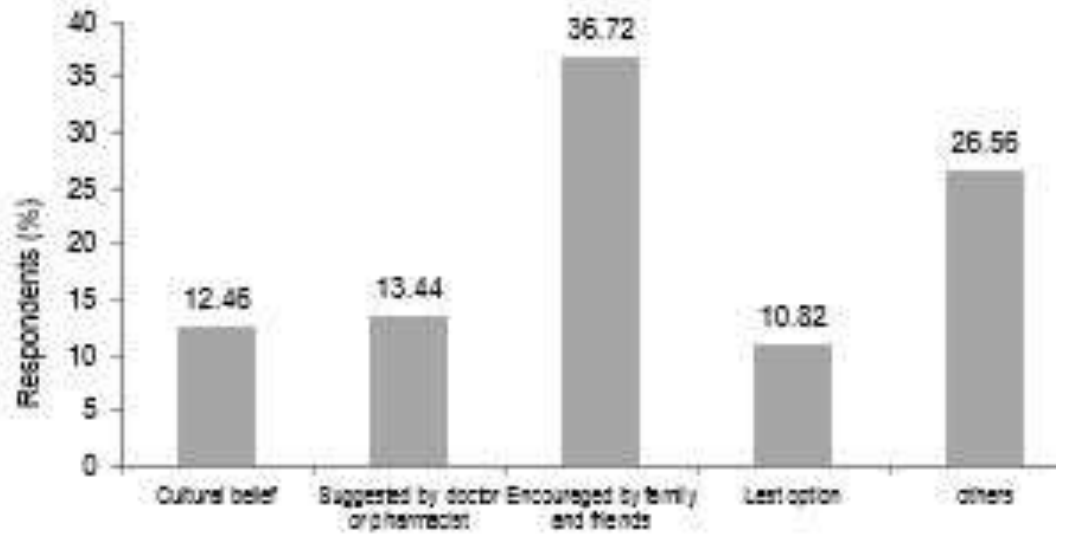

Figure 3: Influence factors on choosingT\&CM versus respondents.

Table 4: Percentage of respondent and health improvement

\begin{tabular}{lccc}
\hline \multicolumn{4}{c}{ Claims of the improvement after using T\&CM. } \\
\hline & & Frequency & Percent \\
Claim & Yes & 261 & 85.57 \\
of improvement & No & 42 & 13.77 \\
Total & Neutral & 2 & 0.66 \\
\hline
\end{tabular}

Table 4 shows the respondents' view on the improvement of their health status when using T\&CM. High percentage of respondents $(85.57 \%)$ claimed that there was an improvement of their health condition after using T\&CM. This result shows a significant claim which $p$ value is $<0.5)$. However, $13.7 \%$ said that T\&CM did not improve their health status while $0.66 \%$ did not give any answer. In general, most of the respondents agreed that T\&CM in whichever ways has increased their health status.

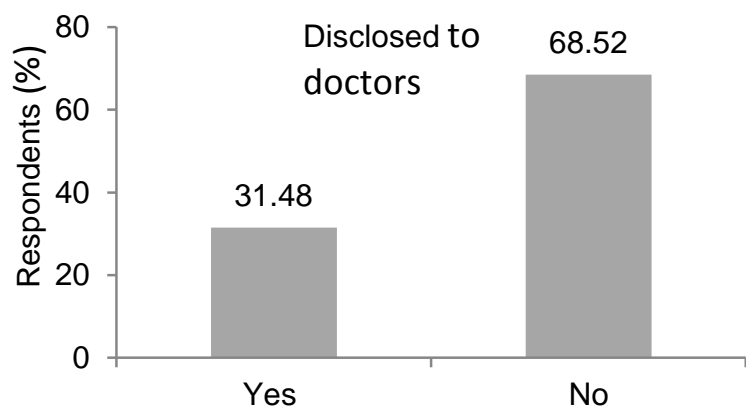

Figure 4: Respondent's disclosure to their doctors on T\&CM usage. 
The respondents were asked on their awareness to disclose the T\&CM usage to their doctors. From figure 4.4, it shows that only $31.48 \%$ of respondents disclosed their T\&CM usage to their doctors. Majority of the respondent $(68.52 \%)$ did not inform their doctors about their T\&CM usages. However, there is no significant difference on the $p$ value.

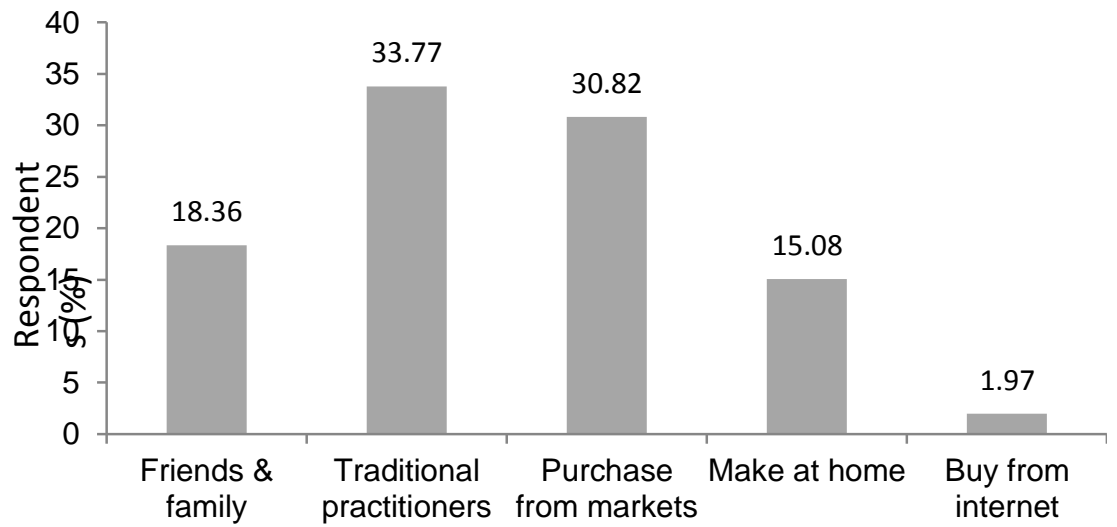

Figure 5: Sources of T\&CM obtained by respondents. Sources of T\&CM obtained

Figure 5 show that respondents obtained their T\&CM from the traditional practitioners mostly. Purchased from market is the next most popular methods of obtaining T\&CM. Small percentage obtained them from friends or family members and produced them at home. A few of them got them from the internet.

Table 5: Knowledge on registered medicines versus age group of respondents.

\begin{tabular}{|c|c|c|c|c|c|c|c|c|}
\hline \multicolumn{9}{|c|}{ Knowledge on registered medicines } \\
\hline & & \multicolumn{6}{|c|}{ Age group (years old) } & \multirow[t]{2}{*}{ Total } \\
\hline & & $<20$ & $20-29$ & $30-39$ & $40-49$ & $50-59$ & $>60$ & \\
\hline \multirow{2}{*}{$\begin{array}{l}\text { Knowledge on } \\
\text { registered } \\
\text { medicines }\end{array}$} & Yes & $\begin{array}{c}20 \\
6.56 \%\end{array}$ & $\begin{array}{c}60 \\
19.67 \%\end{array}$ & $\begin{array}{c}35 \\
11.48 \%\end{array}$ & $\begin{array}{c}41 \\
13.44 \%\end{array}$ & $\begin{array}{c}42 \\
13.77 \%\end{array}$ & $\begin{array}{c}16 \\
5.24 \%\end{array}$ & $\begin{array}{c}214 \\
70.16 \%\end{array}$ \\
\hline & No & 20 & 24 & 9 & 12 & 16 & 10 & $\begin{array}{c}91 \\
29.84 \%\end{array}$ \\
\hline \multicolumn{2}{|l|}{ Total } & 40 & 84 & 44 & 53 & 58 & 26 & $\begin{array}{c}305 \\
100 \%\end{array}$ \\
\hline \multirow{4}{*}{$\begin{array}{l}\text { Percentage of } \\
\text { each age group }\end{array}$} & Yes & $50 \%$ & $71.4 \%$ & $80 \%$ & $77.4 \%$ & $72.4 \%$ & $61.5 \%$ & 214 \\
\hline & No & $50 \%$ & $28.6 \%$ & $20 \%$ & $22.6 \%$ & $27.6 \%$ & $38.5 \%$ & 91 \\
\hline & \multicolumn{8}{|r|}{305} \\
\hline & & & & & & & & $100 \%$ \\
\hline
\end{tabular}


The result from table 5 shows that most of the respondents regardless of age group were aware of the importance of using the registered medicine. However,age groups of 30 to 39 were more aware of the issue. Maybe this group of respondents more exposed to mass media and education program provide by the government. However, there is no significant difference in $p$ value.

Table 6: Awareness on the interaction(s) risk between prescribed medicines and traditional medicine with age group of respondents.

\begin{tabular}{|c|c|c|c|c|c|c|c|c|}
\hline \multicolumn{9}{|c|}{ Awareness on the interaction risk between prescribed medicine and T\&CM. } \\
\hline & & \multicolumn{6}{|c|}{ Age group } & \multirow[t]{2}{*}{ Total } \\
\hline & & $<20$ & $20-29$ & $30-39$ & $40-49$ & $50-59$ & $>60$ & \\
\hline \multirow{3}{*}{$\begin{array}{l}\text { Awareness } \\
\text { on } \\
\text { prescribed } \\
\text { medicine } \\
\text { and T\&CM }\end{array}$} & Yes & $\begin{array}{c}18 \\
5.90 \\
\%\end{array}$ & $\begin{array}{c}62 \\
20.33 \\
\%\end{array}$ & $\begin{array}{c}38 \\
12.46 \\
\%\end{array}$ & $\begin{array}{c}37 \\
12.13 \%\end{array}$ & $\begin{array}{c}42 \\
13.77 \\
\%\end{array}$ & $\begin{array}{c}16 \\
5.25 \%\end{array}$ & $\begin{array}{c}213 \\
(69.84 \% \\
)\end{array}$ \\
\hline & No & 22 & 22 & 6 & 16 & 16 & 10 & $\begin{array}{c}92 \\
(30.16 \% \\
\quad)\end{array}$ \\
\hline & & 40 & 84 & 44 & 53 & 58 & 26 & 305 \\
\hline \multirow{6}{*}{$\begin{array}{c}\text { Percentage } \\
\text { of each age } \\
\text { group }\end{array}$} & Yes & $\begin{array}{c}51.5 \\
\%\end{array}$ & $73.8 \%$ & $86.4 \%$ & $69.8 \%$ & $72.4 \%$ & $61.5 \%$ & 213 \\
\hline & & & & & & & & $\begin{array}{c}(69.84 \% \\
)\end{array}$ \\
\hline & No & $\begin{array}{c}48.5 \\
\%\end{array}$ & $26.2 \%$ & $13.6 \%$ & $30.2 \%$ & $27.6 \%$ & $38.5 \%$ & 92 \\
\hline & & & & & & & & $\begin{array}{c}30.16 \% \\
\quad \\
\end{array}$ \\
\hline & & & & & & & & 305 \\
\hline & & & & & & & & $100 \%$ \\
\hline
\end{tabular}

Table 6 shows that respondents of the younger age group have the least knowledge on the interaction risk between prescribed medicine and T\&CM. Maybe this is due to their lack of exposure to mass media and the education programs as described above.

\subsection{Conclusion}

Our finding suggested that both males and females are T\&CM users. This is in line with the statement made in the book written by the Ministry of Health Malaysia (MOH) that T\&CM has made a significant contribution to the health care of the Malaysian community. It continues to patronizing our people in their bid to seek treatment for diseases and in maintaining health. In a recent study by Z.M.Siti et al. 2009, found that the prevalence of use of T\&CM amongst Malaysians in their lifetime was $69.4 \%(67.6-71.2 \%)$ and $55.6 \%(53.8-57.4 \%)$ within the last period of 12 months of the study. 
Age groups of 20 to 29 were the primary users of T\&CM. It is supported by the fact that people start to develop an attitude toward their health from this age period. The senior citizens were the least users may be due to the more frequent interaction with doctors make them more warned about the interaction that might occur. Senior citizens visited the doctors more often for various conditions that make them have more interaction with doctors.

Most of the respondents are Sabah native due to this study was conducted in Sabah where Malays, Chinese and other races arethe minority group of people in East Malaysia. This major population contributed to the reason why Sabah native is the major users of T\&CM. Another suggestion is the area where Sabah native live could be the explanation of the high consuming among them. They can quickly access to local herbs that are prepared in home or purchase at a nearby roadside.

The reason for using T\&CM was for disease treatment. This is maybe due to the easy access and cheaper price make them opt for T\&CM.

Most of the users take T\&CM after a strong courage from their family members. Even though, there are suggestion from doctors and friends the percentages are low. Some doctors are still not encouraging their patients to take T\&CM due to lack of scientific evidence on the safety and efficacy. However study on various natural products from traditional Chinese medicine (TCM) have been shown to safely suppress proinflammatory pathways and control inflammation-associated disease.this support the evident of T\&CM efficacy on the treatment of disease (Pan,M.H, et al 2011).

The low percentages of disclosing their T\&CM use to their doctors showing that they are not confident on the safety of T\&CM by disclosing the users to their doctors, they afraid that they might be advised to stop the medication or scolded by their doctors. This is a typical of Eastern culture who don't like to share their belief and perception on many things especially related to their diseases.

The highest number of respondents preferred to purchase their medications from traditional practitioners whom they belief as healers of their diseases. This statement is supported by Razali and Yasin (2008) who stated that patients preferred to seek traditional practitioners to treat their disease due to some healers were so well known, and their credibility was so high that people come from near and far to get their disease treatment. There are some respondents who claimed that they buy traditional medicine from the market and internet, due to easy access and cheaper price. There is a small group of respondents who make the medicine at home for mild symptom like headache, food poisoning, bruises and, etc.

From the result obtained also showed that a small percentage of respondents were not aware of the existing of the medicine in the market. This figure is considered as high as the education program related to the registered medicine is available everywhere through mass media and internet. More education program is recommended to be conducted to ensure that all population alert and aware of the registered medicine available in the market including T\&CM.

Respondents from the age group below 20 are less aware on the possible interaction that might occur when combining the medicine or using T\&CM in place of modern medicine. The 
elderly are more vulnerable to drug interaction risk according to Bresslers (2005) who mentioned that changes in body chemistry can cause inhibition of drug metabolism which increase the level of the parent drug, prolonged drug effect and increase drug toxicity. He also stated that competition site for drug metabolism enzyme by two or more drugs can result in decreased inactivation of one of the drugs and an increase and prolongation of drug effect that is toxicity.

Multiple suggestions are available in the $\mathrm{MOH}$ webpage regarding other alternatives available for health maintenance rather than taking medicine. Balance diet is also vital for a healthy health. People have to alert on the latest issue related to medicine to maintain their good health. Despite the facts that the positive physical and psychological benefits of exercise are well documented and well publicized, levels of physical inactivity are still increasing worldwide (Pretty et al.,2007). According to the WHO (2013), $60 \%$ of the world's population does not achieve the minimum amount of daily physical activity needed to bring about health benefits. Thus, the promotion of a healthy lifestyle or health seeking behavior is an effective way to reduce or avoid the medical expenses of treating such preventable diseases associated with lifestyle behaviors. (Mazlina Mansor and Nor Zalina Harun 2014).

This study concluded that Traditional and Complementary medicine are widely used by majority of the patients in Malaysia with little concern on the risk and drug interaction effects that might occur. For example herbal galactagogue were widely used among mothers to increase lactation and its effective. (Nursyuhadah Othman et al 2014). Most of them remain dedicated to their practices due to lack of awareness and high belief on the treatment effectiveness.. A few of them were recommended by their own doctors as a last alternative after various treatments seem not working well. It is very hard to control this practice because the T\&CM methods sometimes work well in certain disease. The efficacy and safety of T\&CM treatment are not yet well documented. Patients are left in a dilemma whether to follow doctor's advice or to listen to those who had vast experience on T\&CM. More studies are proposed to be conducted on T\&CM to ensure the safety and efficacy of the treatment so that the patients will not be kept in dilemma when the alternative treatments are available for their options. Ministry of Health should play their role in conducting more effective education program on the correct way of using T\&CM medicines.

\section{Acknowledgement}

The authors would like to acknowledge University of Technology MARA Malaysia for funding the presentation of this paper.

\section{References}

Bressler, R. (2001). Herb-drug Interactions-Interactions Between Ginkgo Biloba and Prescription Medications. Retrieved on April 2005, from http://geriatrics.modernmedicine.com/geriatrics/data/articlesstandard/geriatrics/152005. 
GBW Lee, TC Charn, ZH Chew and TP Ng. (2004). Quality of care and patient satisfaction. Complementary and alternative medicine use in patients with chronic diseases in primary care is associated with perceived quality of care and cultural beliefs. Family Practice (2004) 21 (6): 654-660 first published online November 5, 2004 doi:10.1093/fampra/cmh613

Lao, L., Bergman, S., Langenherg, P., Wong,R., \& Berman, B. (1995). Oral surgery, oral medicine, oral pathology. Efficacy of Chinese.

Mazlina Manso and Nor Zalina Harun (2014). Health Issues and Awareness, and the Significant of Green Space for Health Promotion in Malaysia - Social and Behavioral Sciences 153. 209 - 220.

Nursyuhadah Othman, Roz Azinur Che Lamin and Che Noriah Othman (2014). Exploring Behavior on the Herbal Galactagogue Usage among Malay Lactating Mothers in Malaysia.Procedia - Social and Behavioral Sciences 153 ( 2014 ) $199-208$

\section{Pan, M.-H. ${ }^{a}$, Chiou, Y.-S. ${ }^{a}$, Tsai, M.-L.a, Ho, C.-T. (2.011) ${ }^{b}$ Anti-inflammatory activity of traditional chinese medicinal herbs. Journal of Traditional and Complementary Medicine. 1(1), 8-24.}

Razali, S.M., \& Yassin, A.M. (2008). Complementary Treatment of Psychotic and Epileptic Patients in Malysia. Transcultural Psychiatry, 45(3), 455-469.doi:10.1177/136.

Siti, Z.M., A., Farah.,Fazlin, S.M., Sondi,S.,Azman,A.H., Zaleha, W.C, (2009). Use of Traditional and Complementary Medicine in Malaysia: A baseline Study: Retrieved on November 9, 2009. From http://ncbi.nlm.nih.gov/pubmed/19942109.

Suzanne M. B, Christina C. W, Ellen P. M. July (2008). Use of Complementary and Alternative Therapies by Overweight and Obese Adults. Retrieved on 17 July 2014. www.obesityjournal.org

WHO (2002). Traditional Medicine Strategy 2002-2005, World Health Organization (WHO). Geneva Retrieved from http://whqlibdoc.who.int/hq/2002/who_edm_trm_2002.1.pdf 